\title{
Governança Corporativa: Análise Bibliométrica do Período de 2000 a 2012
}

\section{Gobierno Corporativo: 2000 Período de Análisis bibliométrico de 2012}

\section{Corporate Governance: 2000 Period Bibliometric Analysis to 2012}

\author{
Sady Mazzioni \\ Professor Titular da Universidade Comunitária da Região de \\ Chapecó, Endereço: Avenida Senador Attílio Fontana 591 E, \\ Bloco R, EFAPI, CEP: 89.809-000 - Chapecó, SC - Brasil \\ Telefone: (49) 33218243, e-mail: $\underline{\text { sady@unochapeco.edu.br }}$ \\ Everton Paulo Folletto \\ Endereço: Avenida Senador Attílio Fontana 591 E, Bloco R, \\ EFAPI, CEP: 89.809-000 - Chapecó, SC - Brasil \\ Telefone: (49) 33218243, e-mail: \\ clesia@unochapeco.edu.br
}

\author{
Clésia Ana Gubiani \\ Professora da Universidade Comunitária da Região de \\ Chapecó, Endereço: Avenida Senador Attílio Fontana 591 E, \\ Bloco R, EFAPI, CEP: 89.809-000 - Chapecó, SC - Brasil, \\ Telefone: (49) 33218243, e-mail: clesia@unochapeco.edu.br \\ Silvana Dalmutt Kruger \\ Doutorando em Ciências Contábeis, Universidade Federal de \\ Santa Catarina, UFSC, Brasil. \\ Endereço: Universidade Comunitária da Região de Chapecó, \\ Av. Senador Atílio Fontana, EFAPI, CEP: 89.809-000, Chapecó, \\ SC - Brasil - Caixa-postal: 747 \\ Telefone: (49) 33218243, e-mail: silvanak@unochapeco.edu.br
}

\section{RESUMO}

Este estudo tem por objetivo mapear o perfil das publicações nos periódicos e congressos da área contábil, no período de 2000 a 2012, sobre governança corporativa. Para tanto, realizou-se uma pesquisa de caráter descritivo, com procedimento documental e com a abordagem quantitativa do problema. Para a análise dos dados, utilizou-se do software UCINET $^{\circledR}$ para a elaboração de redes, tanto para aspectos gerais como metodológicos. Verificou-se que o maior número de publicações ocorreu em 2011 e a quantidade mais recorrente foi de três autores por estudo. Constatou-se, também, que quanto aos aspectos metodológicos as formas mais predominantes nos estudos analisados referem-se às pesquisas descritivas, documentais, quantitativas e com análise documental. Por fim, sugere-se que estudos sobre Governança Corporativa devem ser explorados de forma mais consistente no meio acadêmico brasileiro, tendo em vista que a grande parte dos estudos paira em aspectos gerais e menos aprofundados.

Palavras-chave: Governança corporativa. Pesquisa bibliométrica. Publicações.

\section{ABSTRACT}

This study aims to map the profile of publications in journals and conferences from the accounting area, from 2000 to 2012 on corporate governance. For this, we carried out a survey of descriptive character with documented procedure and quantitative approach to the problem. For data analysis, we used the UCINET ${ }^{\circledR}$ software for developing networks, both general and methodological aspects. It was found that the largest number of publications occurred in 2011, and recurring amount was three authors of the study. It was found also that in methodological terms the most prevalent forms in the analyzed studies refer to the descriptive, documentary, documentary analysis and quantitative research. Finally, it is suggested that studies on Corporate Governance

\footnotetext{
${ }^{1}$ Artigo recebido em 13.12.2013. Revisado pelos pares em 15.04.2014 (blind review). Ajustado e Aceito para publicação em 06.12.2014. Recomendado para publicação por José Ribamar Marques de Carvalho (Editor Científico). Publicado em 15.12.2014. Organização responsável PROFIAP/CCJS/UFCG.
} 
should be used more consistently in the Brazilian academia, considering that most studies hovers in general and less detailed aspects.

Keywords: Corporate Governance. Bibliometric research. Publications.

\section{RESUMEN}

Este estudio tiene como objetivo trazar el perfil de las publicaciones en revistas y conferencias en materia de contabilidad, de 2000 a 2012 en el gobierno corporativo. Por lo tanto, se realizó una investigación descriptiva con procedimiento documentado y el enfoque cuantitativo para el problema. Para el análisis de los datos, se utilizó el software UCINET® para el desarrollo de redes, tanto los aspectos generales como metodológico. Se encontró que el mayor número de publicaciones se produjo en el año 2011, la cantidad más recurrente fue de tres autores del estudio. También se constató que en los aspectos metodológicos de las formas más frecuentes en los estudios analizados se refieren a la investigación descriptiva, documental, análisis cuantitativo y documento. Por último, se sugiere que los estudios sobre gobierno corporativo deben ser explotados de manera más consistentes en la académica brasileña, dado que la mayoría de los estudios se cuelga en aspectos generales y menos detalladas.

Palabras clave: Gobierno Corporativo. Análisis Bibliométrico. Publicaciones.

\section{INTRODUÇÃO}

Com as constantes mudanças que as organizações estão vivenciando decorrente de um novo cenário global, os estudiosos passaram a concentrar maior atenção em novos temas, como a Governança Corporativa. A principal mudança que levou a um estudo mais aprofundado deste tema está relacionada à recente percepção da necessidade de atrair investidores como uma das alternativas de financiamento.

De acordo com Souza (2005), a governança corporativa surgiu inicialmente nos Estados Unidos, como uma tendência decorrente da pressão de fundos de pensão que passaram a exigir mais informação e transparência das companhias, visando impor limites aos abusos dos controladores. Assim, as boas práticas de governança corporativa podem ser percebidas como algo necessário para suprir novas tendências das organizações, como os impactos da separação entre a gestão e a propriedade.

No Brasil, de acordo com Rosseti e Andrade (2012), o desenvolvimento da Governança Corporativa deve-se a um amplo conjunto de fatores que levou à revisão das condições institucionais e dos processos de governança das empresas a partir dos anos 90 e, mais fortemente, na virada do século, entre elas as exigências decorrentes de abertura do mercado para a participação mais ativa dos investidores institucionais nas empresas. Silva (2010) ainda complementa apontando que as privatizações demonstram as primeiras experiências de controle compartilhado no Brasil.

A Governança Corporativa busca minimizar os conflitos e custos que podem surgir diante de organizações de controle compartilhado. Assim, a governança corporativa pode ser entendida como um conjunto de mecanismos por meio dos quais se atribuem responsabilidades, criando órgãos que visam observar princípios e 
práticas com vistas a assegurar direitos à comunidade interna (como acionistas minoritários e empregados) e comunidade externa (como fornecedores e clientes), permitindo uma melhor percepção dos objetivos da empresa e das formas de atingilos e propiciando uma eficiente fiscalização do desempenho da sociedade. Diante do exposto elaborou-se o seguinte problema de pesquisa: Qual o perfil das publicações nos periódicos da área contábil, no período de 2000 a 2012, sobre governança corporativa?

Nesse intuito, o objetivo desta pesquisa é identificar o perfil das publicações nos periódicos e congressos da área contábil, no período de 2000 a 2012, sobre governança corporativa. Para tanto, realizou-se uma pesquisa descritiva, documental e com abordagem quantitativa. Para a análise conjunta dos dados elaboraram-se redes dos itens pesquisados em cada estudo, com a utilização do software UCINET ${ }^{\circledR}$.

O estudo da Governança Corporativa justifica-se pela agregação de valor que pode trazer para a organização. Pode-se verificar tal fato observando estudos que buscam avaliar as relações existentes entre boas práticas de governança corporativa com desempenho e imagem da organização.

\section{REFERENCIAL TEÓRICO}

\subsection{ABORDAGENS DA GOVERNANÇA CORPORATIVA}

A Governança Corporativa, segundo Silva (2010), tem como finalidade aperfeiçoar o desempenho de uma companhia por meio de um conjunto de práticas, protegendo investidores, empregados e credores, com vistas a facilitar o acesso ao capital. Nesse sentido, Silva (2006, p. 5) define a governança corporativa como:

\footnotetext{
Um conjunto de princípios e práticas que procura minimizar os potenciais conflitos de interesse entre os diferentes agentes da companhia (stakeholders) com o objetivo de reduzir o custo de capital e aumentar tanto o valor da empresa quanto o retorno aos seus acionistas.
}

O Instituto Brasileiro de Governança Corporativa (IBGC), órgão criado em 1995, tem como objetivo disseminar o conceito de governança e incentivar o melhor desempenho das organizações. O IBGC define a Governança Corporativa como:

O sistema pelo qual as organizações são dirigidas, monitoradas e incentivadas, envolvendo os relacionamentos entre proprietários, conselho de administração, diretoria e órgãos de controle. As boas práticas de governança corporativa convertem princípios em recomendações objetivas, alinhando interesses com a finalidade de preservar e otimizar o valor da organização, facilitando seu acesso ao capital e contribuindo para a sua longevidade (IBGC, 2009, p. 19). 
A importância da Governança Corporativa foi crescente ao longo do século XX. Na virada do século XIX, no entendimento de Rosseti e Andrade (2012), os fundadores das empresas, mesmo daquelas que recorreram à sociedade anônima como forma de constituição e de capitalização, estavam presentes nas empresas e dispunham de diversos instrumentos para o seu controle e exerciam o comando. No entanto, ao longo do século XX, os processos sucessórios, o avanço das sociedades anônimas de capital aberto e o desenvolvimento do mercado de capitais mudaram a estrutura de poder nas companhias.

Com esta nova forma de gestão, na qual há a pulverização da propriedade e a dispersão do número de acionistas, pode-se concluir, então, que a Governança, sendo constituída de forma bilateral - propriedade e gestão - deve buscar minimizar por meio das boas práticas de governança corporativa os possíveis conflitos existentes entre estas duas funções a fim de aumentar tanto o valor da empresa quanto o destinado a seus acionistas.

Nos últimos anos, mais precisamente a partir da década de 1980, as relações entre o mundo corporativo e a sociedade, entre as empresas de uma mesma cadeia de negócios, e entre os acionistas, os conselhos e a direção executiva, têm se modificado de forma substancial. O principal foco da governança, neste cenário de mudanças, tem sido, portanto, a análise dos objetivos das companhias, tendo em vista suas interfaces com as demandas e os direitos dos stakeholders (ROSSETI; ANDRADE, 2012).

Os stakeholders, sendo o conjunto de pessoas, grupos ou instituições que têm interesses por certa empresa, que afetam e são afetados pelas diretrizes decididas por esta empresa, são elementos vitais para a existência das organizações, pois além de ser a própria organização (acionistas, funcionários), representam o contexto em que ela está inserida (governo, credores, consumidores). Desta forma, nota-se que a governança não deve buscar atender apenas determinados grupo de interesses, mas sim, todo o conjunto de stakeholders. Sob essa perspectiva, Bruère et al. (2007, p. 150) destacam que tais práticas possibilitariam uma maior confiança e menor percepção de risco por parte dos diversos shareholders e stakeholders, expressas na transparência com que as companhias passassem a divulgar seus resultados, nas suas auditorias independentes e no respeito às leis que protegem os direitos dos acionistas minoritários e credores.

As práticas iniciais de governança corporativa, segundo Punsuvo et al. (2007), "foram estabelecidas como resposta a diversos problemas referentes ao relacionamento entre os acionistas e as empresas, a constituição dos conselhos de administração e a atuação da diretoria executiva". No mesmo sentido, Rosseti e Andrade (2012, p. 130), apontam que "no seu nascedouro, a governança fixou-se nos conflitos de agência entre acionistas e gestores e entre grupos majoritários e minoritários de controle das companhias". Estes dois tipos de conflito decorreram principalmente pelo divórcio do controle e da gestão, e pela dispersão da 
propriedade seguida da concentração na mão de alguns, levando ao conflito com aqueles que não possuem o controle.

No entanto, de acordo com mesmos autores, a mudança nas relações entre as corporações e a sociedade, com a consequente revisão dos objetivos corporativos, surgiram-se várias novas concepções de conteúdo mais amplo, não apenas derivadas de pressões ativistas, mas também das diferenças culturais e institucionais entre os países, como concepções limitadas aos interesses dos proprietários, centrada na gestão de interesses internos ampliados, aberta a outras partes interessadas, integradas na cadeia de negócios, aberta à conciliação dos proprietários com as demandas do conjunto de stakeholders: internos, externos e situados no entorno das corporações, entre outras. Conforme Rosseti e Andrade (2012), todas estas diferentes concepções, todavia, mantêm um mesmo objetivo: o de proporcionar no longo prazo o máximo retorno do capital integralizado pelos sócios, harmonizados com os interesses de outros stakeholders.

De acordo com Rosseti e Andrade (2012), os valores que dão sustentação a governança corporativa podem ser divididos em quatro: fairness, disclousure, accountability e compliance. O primeiro versa pela igualdade no tratamento dos acionistas, sejam majoritários ou minoritários; já o segundo, diz respeito a transparência das informações, em especial as que impactam os negócios e que envolvem resultados, oportunidades e riscos; o terceiro aborda a prestação de contas responsável, de acordo com as melhores práticas contábeis e de auditoria; finalmente, o quarto, versa acerca da conformidade no atendimento de normas reguladoras, expressas nos estatutos sociais, nos regimentos internos e nas instituições legais do país.

\subsection{GOVERNANÇA CORPORATIVA NO BRASIL}

Conforme relata Araujo (2010), uma das razões mais fortes para o crescimento da governança corporativa no Brasil foi a participação cada vez mais crescente dos fundos de pensão nas empresas brasileiras. De acordo com este autor, seria impossível imaginar um fundo de pensão investir maciçamente em empresas e não meios formais e expressivos de conhecer a realidade empresarial. Apontando outros fatores, Silva (2010) expõe que a governança corporativa desenvolveu-se no Brasil em resposta ao movimento pelas boas práticas de governança corporativa e à necessidade das empresas modernizarem sua alta gestão, com o objetivo de tornarem-se mais atraentes para o mercado. E complementa: "O fenômeno foi acelerado pelos processos de globalização, privatização e desregulamentação da economia, que resultaram em um ambiente corporativo mais competitivo" (p. 32).

Rosseti e Andrade (2012, p. 449) afirmam que um amplo conjunto de fatores levou à revisão das condições institucionais e dos processos de governança das empresas a partir dos anos 90 e, mais fortemente, na virada do século, entre elas as 
exigências decorrentes de abertura do mercado à participação mais ativa dos investidores institucionais nas empresas. Sob essa perspectiva, Silva (2010) complementa ainda que as privatizações demonstram as primeiras experiências de controle compartilhado no Brasil. Nessas empresas, os investidores integrantes do grupo de controle passaram a dividir o comando da empresa, estabelecendo regras contratualmente.

Os investidores institucionais (seguradoras, fundos de investimentos, etc.) assumiram uma postura ativa passando a exercer o direito de voto de suas ações e a fiscalizar de modo mais próximo a gestão das companhias investidas. Quanto ao mercado financeiro, houve também aumento de investimentos de estrangeiros no mercado de capitais, o que reforçou a necessidade das empresas se adaptarem às exigências e padrões internacionais. Em síntese, as práticas de governança corporativa tornaram-se prioridade e fonte de pressão por parte dos investidores (SILVA, 2010).

Em razão desta nova necessidade recém-surgida, foi publicado em 1999 o primeiro Código das boas práticas de governança corporativa, pelo IBGC. Seguido deste fato, fez-se outros estímulos às adoções de boas práticas de governança corporativa, como a Cartilha da CVM (Comissão de Valores Mobiliários) sobre este tema, a diferenciação de níveis de governança entre as empresas cotadas na Bovespa, prêmios, etc. Entretanto, para Silva (2010), apesar do aprofundamento dos estudos sobre governança e da crescente pressão para adoção das boas práticas, o Brasil ainda se diferencia pela alta concentração de controle acionário, pela baixa efetividade dos conselhos de administração e pela alta sobreposição entre propriedade e gestão.

O estudo realizado por Nardi e Nakao (2008), verificou o impacto da entrada da empresa nos níveis diferenciados de Governança Corporativa sobre a imagem institucional da mesma, ou ainda a pesquisa feita por Almeida et al. (2010), na qual teve como objetivo investigar a relação entre a qualidade das práticas de governança corporativa e o desempenho das empresas brasileiras de capital aberto não listadas em bolsa de valores, por exemplo. Tendo em vista que em ambas as pesquisas a hipótese inicial foi confirmada, conclui-se que os princípios e as práticas de governança corporativa poderão trazer tanto resultados mensuráveis como que ainda não se pode mensurar.

Outros estudos relevantes ligados a governança corporativa, como o de Pedreira e Santos (2004) e Batistella et al. (2004) apontam, no entanto, que não há relação entre a adesão de práticas diferenciadas de governança corporativa e o desempenho ou a valorização das ações destas empresas. Pelo fato de a atenção dada a este assunto e também à divergência verificada entre aspectos ligados a Governança Corporativa, percebe-se que existe ainda a necessidade de estudos mais específicos e detalhados a respeito deste assunto. 


\subsection{ESTUDOS CORRELATOS}

Em linha com a presente investigação, outras pesquisas também tiveram como escopo o estudo da produção científica a respeito da Governança Corporativa, a exemplo de Souza e Borba (2007), Bianchi et al. (2009) e Campos, Diniz e Martins (2011).

Souza e Borba (2007), nesse sentido, tiveram como objetivo analisar artigos publicados no exterior que discutiam aspectos relacionados à governança corporativa e políticas de remuneração. A análise dos artigos, coletados a partir do Portal Capes, através de bases de dados existentes apontaram o ano de 2005 como o de maior quantidade de publicações sobre o assunto, concentrando-se principalmente em cinco periódicos internacionais da área da administração, tendo como assunto mais debatido a remuneração do executivo principal, e quanto aos países focados nas pesquisas, o destaque é dado ao continente americano, o qual totalizou $66 \%$ da amostra de artigos empíricos.

Bianchi et al. (2009) e Campos, Diniz e Martins (2011), por outro lado, investigaram especificamente os estudos que trataram de governança corporativa. $\mathrm{O}$ primeiro, que teve como objetivo identificar o perfil das pesquisas e a evolução do tema nos artigos apresentados no Encontro da Associação Nacional de PósGraduação e Pesquisa em Administração - EnANPAD, no período de 1999 a 2008, revelou a concentração das pesquisas sobre o tema na área de finanças, com um princípio de pesquisas relacionados a outras áreas a partir de 2003 e uma evolução significativa no número de referências utilizadas no congresso e no número de artigos aprovados sobre o tema no período.

Já o estudo de Campos, Diniz e Martins (2011) buscou, sob uma análise de eminentemente metodológica, identificar e analisar as publicações brasileiras sobre governança corporativa dentro do contexto da contabilidade e finanças, evidenciando as fronteiras de pesquisas: estrutura teórica, mecanismos de accountability, metodologia e técnica aplicada, setores e contexto, globalização e horizonte temporal. Os resultados revelaram que as pesquisas brasileiras sobre governança corporativa têm feito uso quase que exclusivo das fronteiras apontadas como tradicionais. Isto é, indicam que quanto a fronteira da estrutura teórica, a teoria da agência tem sido alvo da maioria das investigações, focando exclusivamente na resolução de conflitos de interesse, quanto aos procedimentos metodológicos, a abordagem dominante para pesquisar e analisar governança corporativa tem envolvido a adoção de metodologia com abordagem empírico-positiva, utilizando como estratégia de pesquisa quaseexperimento, levantamento e estudo de casos etc. 


\section{PROCEDIMENTOS METODOLÓGICOS}

Quanto aos objetivos, esta pesquisa se caracteriza como descritiva, por ter a pretensão de descrever aspectos relacionados à produção científica acerca da governança corporativa no Brasil, no período de 2000 a 2012. Segundo Gil (2008), “a pesquisa descritiva tem como principal objetivo descrever características de determinada população ou fenômeno ou o estabelecimento de relações entre as variáveis".

De acordo com Raupp e Beuren (2004), os procedimentos técnicos utilizados referem-se à maneira pela qual se conduz o estudo e se obtêm os dados da pesquisa. Neste seguindo, ainda segundo os mesmos autores, o presente estudo caracteriza-se como pesquisa documental. As pesquisas do tipo documental baseiam-se em materiais que ainda não receberam tratamento analítico ou que podem ser reelaborados de acordo com os objetivos da pesquisa (RAUPP; BEUREN, 2004).

Por se tratar de uma pesquisa bibliométrica acerca do tema Governança Corporativa, em relação à abordagem do problema, este estudo caracteriza-se como quantitativo. De acordo com Raup e Beuren (2004, p. 92), “a pesquisa abordagem quantitativa caracteriza-se pelo emprego de instrumentos estatísticos, tanto na coleta como no tratamento dos dados".

Para cumprir os objetivos propostos, primeiramente, definiram-se os locais em que seriam pesquisados os artigos analisados. Da mesma forma como Borges et al. (2012) em seu estudo acerca do ensino da Contabilidade, optou-se por trabalhar com periódicos e congressos nesta pesquisa, devido à reconhecida importância desses trabalhos como veículo de divulgação da produção científica brasileira. Os periódicos que serviram de análise podem ser observados no Quadro 1, bem como, o número de artigos encontrados em cada um deles.

Quadro 1 - Periódicos pesquisados e quantidade de artigos

\begin{tabular}{|l|c|}
\hline \multicolumn{1}{|c|}{ Periódico } & \multicolumn{1}{c|}{ № de artigos analisados } \\
\hline ANPCONT & 11 \\
\hline Revista de Administração e Contabilidade da Unisinos & 29 \\
\hline Congresso USP de Controladoria e Contabilidade & 2 \\
\hline Revista de Contabilidade do Mestrado em Ciências Contábeis da UERJ & 6 \\
\hline Revista de Contabilidade e Finanças & 2 \\
\hline Revista de Contabilidade e Organizações & 7 \\
\hline Contabilidade Vista \& Revista & 3 \\
\hline Revista Contemporânea de Contabilidade & 1 \\
\hline Revista ConTexto & 3 \\
\hline Enfoque: Reflexão Contábil & 1 \\
\hline Revista de Informação Contábil & 2 \\
\hline Pensar Contábil & 5 \\
\hline Revista de Administração de Empresas & 1 \\
\hline Sociedade, Contabilidade e Gestão & 3 \\
\hline Universo Contábil & 82 \\
\hline Total & \\
\hline
\end{tabular}

Fonte: Dados da pesquisa. 
As pesquisas realizadas nos periódicos foram feitas pelo título, utilizando como índex de busca o termo Governança Corporativa, com exceção da Revista de Administração de Empresas, em que, pela impossibilidade da procura por título, buscou-se o mesmo termo nas palavras-chave, e também no Congresso USP, em que buscou-se apenas por governança para garantir o efetivo resultado da pesquisa, pois ao buscar-se por Governança Corporativa o mecanismo de busca não encontrava nenhum resultado. Adicionalmente, outros periódicos ainda não ofereciam motor de buscas nos sítios da internet, como a Revista Contemporânea de Contabilidade; Pensar Contábil; Sociedade, Contabilidade e Gestão; ANPCONT e Congresso USP (da primeira a terceira edição), necessitando a busca manual pelos artigos. Outros dois artigos da ANPCONT foram excluídos da análise das pesquisas pelo fato de ser redigido em língua inglesa. O período dos artigos analisados varia de 2000 a 2012. Totalizando, assim, 82 artigos analisados.

Optou-se por subdividir a seção destinada a descrição e análise dos dados em duas subseções. Na primeira subseção, foram apresentados aspectos gerais dos estudos analisados, como vínculos entre autores e co-autores, quantidade de autores por artigo e os anos das publicações. A segunda subseção apresenta os aspectos metodológicos analisados nas pesquisas, observando as tipologias das pesquisas quanto aos objetivos, quanto aos procedimentos, quanto à abordagem do problema, quanto aos instrumentos de pesquisa e quanto a análise dos dados. Para tanto, utilizou-se os aspectos metodológicos abordados por Raupp e Beuren (2004) quanto às tipologias de pesquisa e de Colauto e Beuren (2004) quanto os instrumentos de pesquisa e análise dos dados.

Para melhor explanação dos aspectos analisados, demonstra-se a seguir o quadro construído por Gubiani et al. (2010).

Quadro 2 - Constructo para levantamento das informações sobre os aspectos metodológicos

\begin{tabular}{|l|l|}
\hline \multicolumn{1}{|c|}{ Categorias analisadas } & \multicolumn{1}{c|}{ Subcategorias } \\
\hline Tipologias da pesquisa quanto aos objetivos & $\begin{array}{l}\text { Pesquisa exploratória } \\
\text { Pesquisa descritiva } \\
\text { Pesquisa explicativa }\end{array}$ \\
\hline \multirow{2}{*}{ Tipologias da pesquisa quanto aos procedimentos } & $\begin{array}{l}\text { Estudo de caso } \\
\text { Levantamento ou survey } \\
\text { Pesquisa bibliográfica }\end{array}$ \\
& $\begin{array}{l}\text { Pesquisa experimental } \\
\text { Pesquisa documental } \\
\text { Pesquisa participante }\end{array}$ \\
\hline Tipologias da pesquisa quanto à abordagem do problema & $\begin{array}{l}\text { Pesquisa Qualitativa } \\
\text { Pesquisa Quantitativa }\end{array}$ \\
\hline & Observação \\
Questionários \\
Instrumentos de Pesquisa & Entrevistas \\
& Checklist \\
& Documentação \\
\hline Análise dos dados & Análise de conteúdo \\
& Análise descritiva \\
& Análise documental \\
\hline
\end{tabular}


Fonte: Gubiani et al. (2010).

De acordo com Gubiani et al. (2010), a principal limitação da pesquisa bibliométrica refere-se ao fato de que os resultados da pesquisa não podem ser generalizados, ou seja, restringem-se aos artigos e ao período analisado. E outra limitação refere-se à subjetividade presente na análise de conteúdo, porque esta envolve interpretações e decodificações pessoais por parte do pesquisador.

\section{DESCRIÇÃO E ANÁLISE DOS DADOS}

Nesta seção buscou-se apresentar os aspectos gerais e metodológicos dos artigos pesquisados.

\subsection{ASPECTOS GERAIS DOS ARTIGOS PESQUISADOS}

Apresentam-se nas Figuras 1 a 3 as informações acerca do número de autores por artigos e os anos das publicações. Na Figura 1, é exposta a rede dos autores e coautores.

Figura 1 - Rede dos autores e coautores

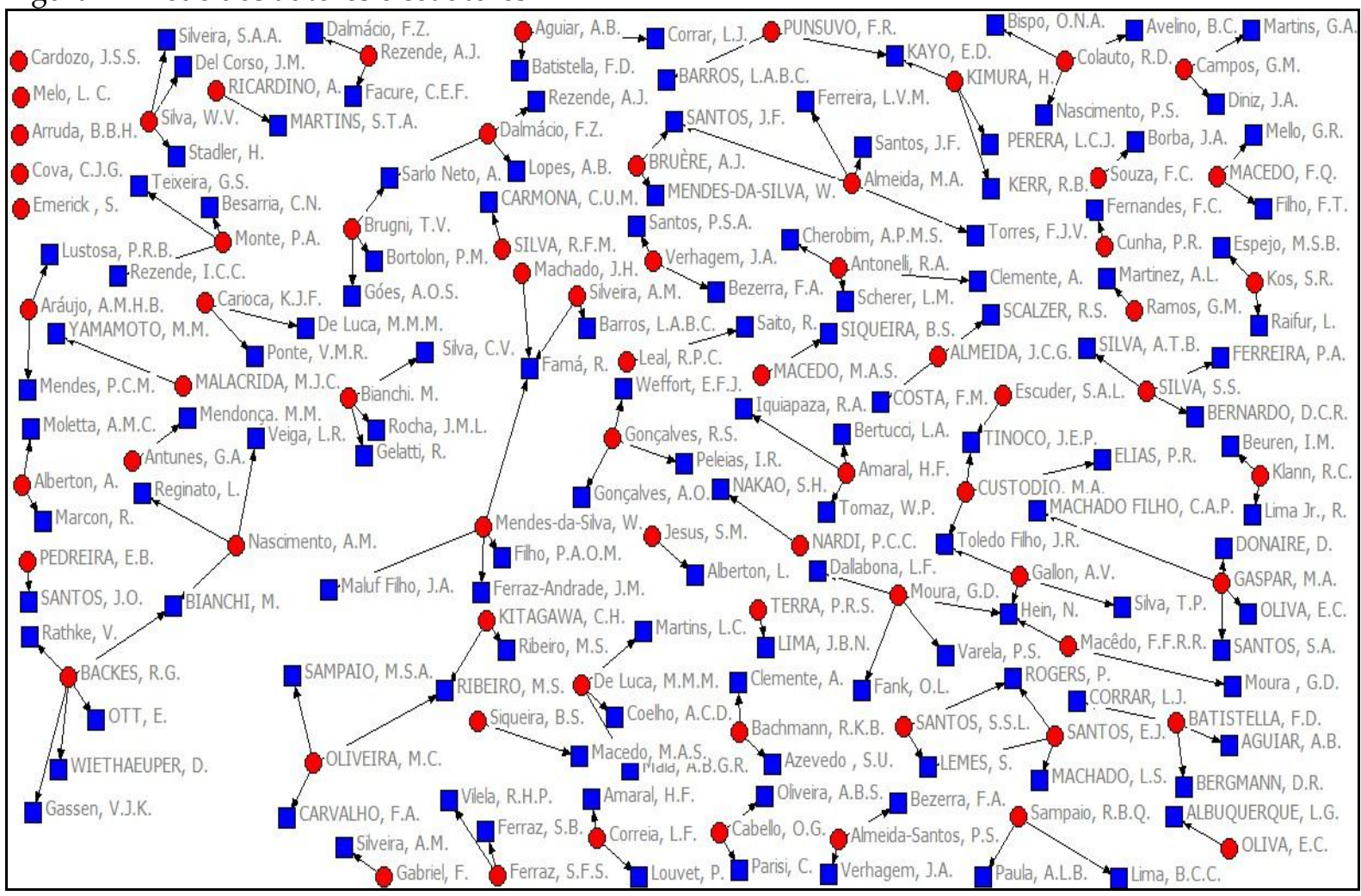

Fonte: Dados da pesquisa.

Conforme a Figura 1, pode-se verificar a autoria dos artigos pesquisados, bem como que, com algumas exceções, a maioria dos coautores possui vinculo a penas um autor. Na Figura 2, são apresentadas a quantidade de autores por artigos. 
Figura 2 - Redes da quantidade de autores em cada artigo

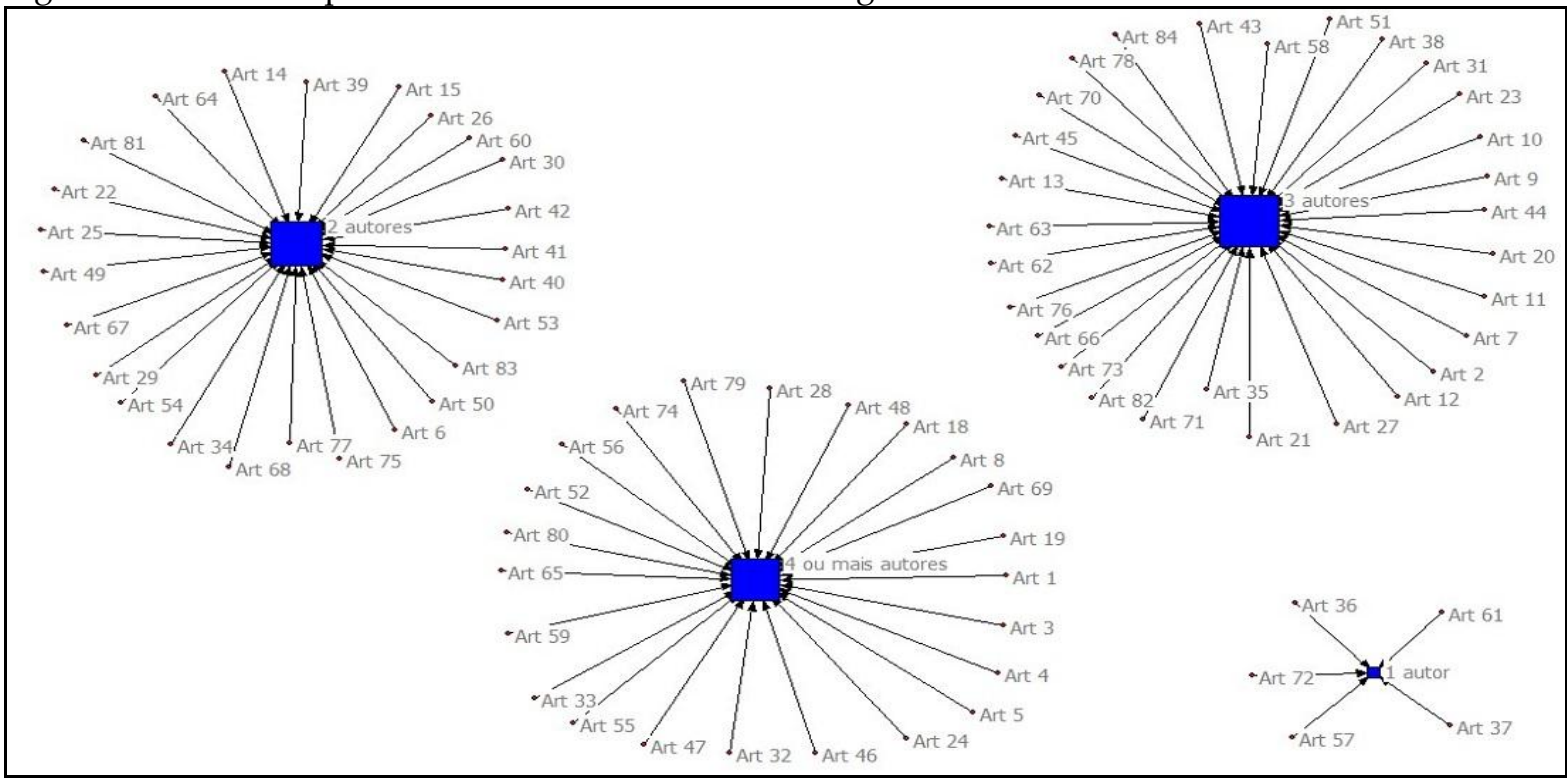

Fonte: Dados da pesquisa.

Conforme a Figura 2 pode-se verificar que quanto ao número de autores por artigo, excetuando-se os artigos escritos por um autor, foi bastante equilibrado, prevalecendo os artigos escritos por três autores com 29 artigos. Na sequência, com 25 artigos, a publicação com dois autores e 23 artigos escritos por quatro ou mais autores. Por fim, os autores escritos por apenas um autor somaram 5 artigos.

A Figura 3 evidencia a quantidade de publicações por ano analisado.

Figura 3 - Redes dos anos publicados

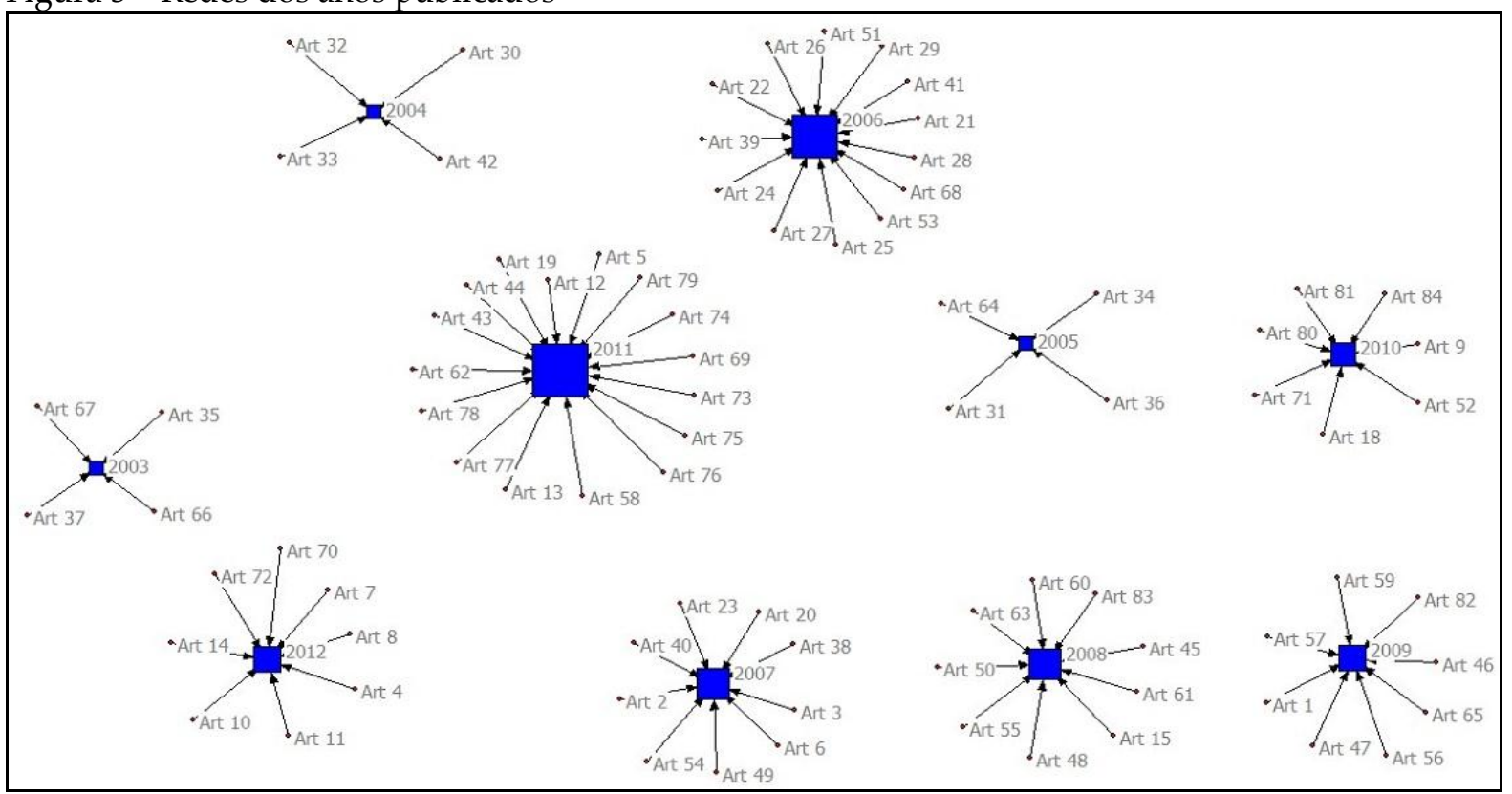

Fonte: Dados da Pesquisa

A partir da observação da Figura 3 pode-se constatar que a maior quantidade de artigos publicados nestas revistas concentra-se nos anos de 2006 e 2011. O Gráfico 1 apresenta a distribuição de frequência dos artigos por ano. 
Gráfico 1 - Distribuição de Frequência dos artigos publicados por ano

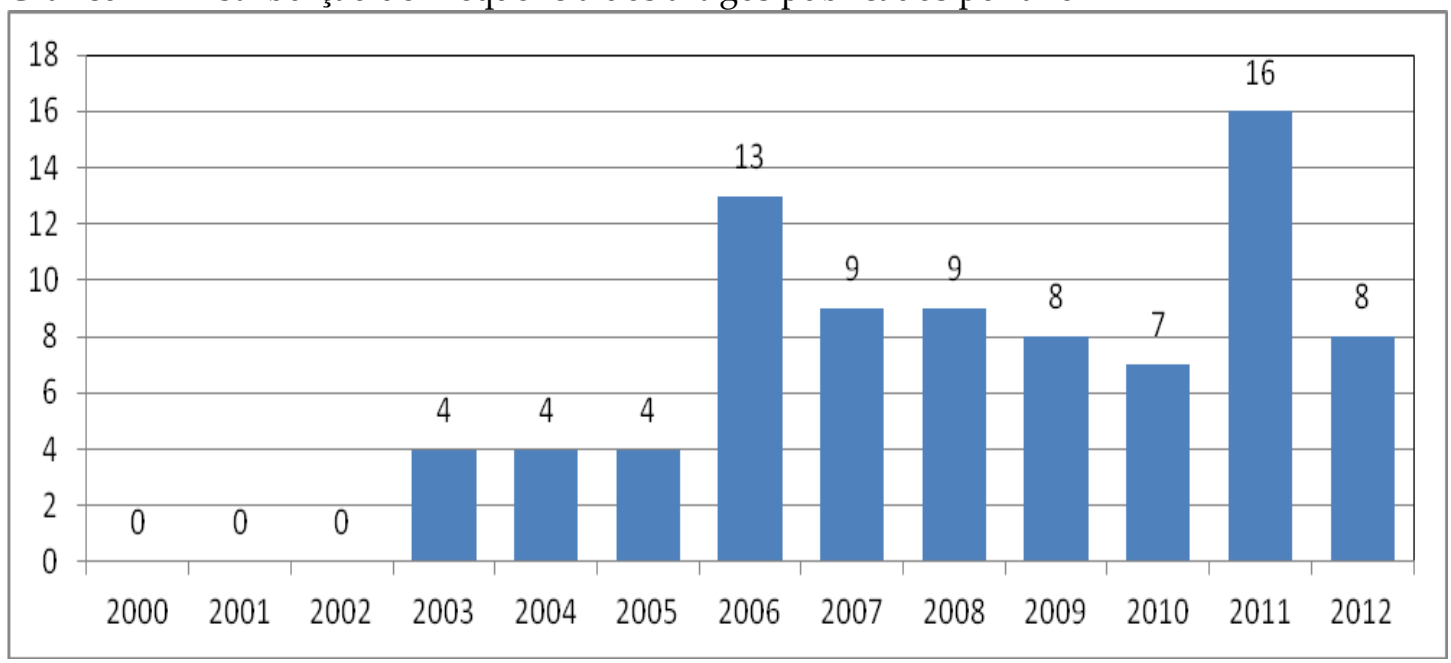

Fonte: Dados da pesquisa.

Percebe-se que a publicação de estudos acerca do tema Governança Corporativa teve um aumento significativo a partir do ano de 2006 e não houve publicações acerca do tema entre os anos de 2000 e 2001, conforme o Gráfico 1.

\subsection{ASPECTOS METODOLÓGICOS DOS ARTIGOS PESQUISADOS}

Nesta seção são apresentados os aspectos metodológicos dos artigos pesquisados, como tipologia dos artigos quanto aos objetivos, quanto aos procedimentos, quanto a abordagem do problema, quanto aos instrumentos de pesquisa utilizados e quanto aos métodos de análise dos dados.

Na Figura 4 apresenta-se a tipologia de pesquisa quanto aos objetivos dos estudos analisados.

Figura 4 - Redes das tipologias das pesquisas quanto aos objetivos

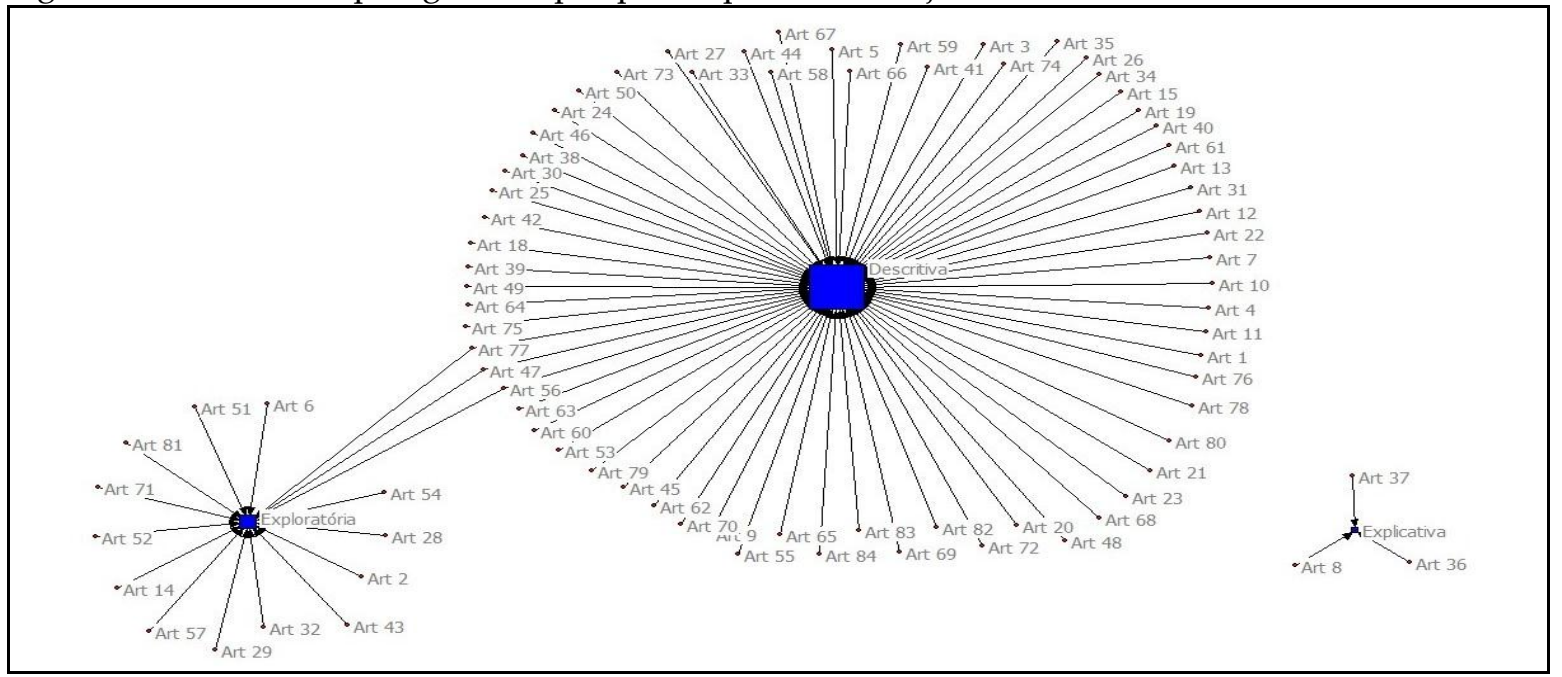

Fonte: Dados da pesquisa.

Observa-se com a Figura 4 que, quanto aos objetivos das pesquisas, existe a preponderância da pesquisa descritiva, sendo que dos 82 artigos analisados, 66 des- 
tes classificaram-se como descritivos. Em seguida, destacaram-se os estudos exploratórios, com 16 pesquisas, e, por fim, os de caráter explicativos, com 3 artigos.

De acordo com Gil (2008), “a pesquisa descritiva tem como principal objetivo descrever características de determinada população ou fenômeno ou estabelecimento de relações entre variáveis". Assim, a pesquisa descritiva preocupa-se em observar fatos, analisá-los e interpretá-los. Desta forma, este resultado era previsível, tendo em vista que os estudos acerca da governança corporativa são recentes e trata-se de uma temática intangível, ainda difícil de mensurar e que carece de maiores estudos sobre suas implicações.

Apresentam-se, na Figura 5, as tipologias das pesquisas quanto aos procedimentos utilizados.

Figura 5 - Redes das tipologias das pesquisas quanto aos procedimentos

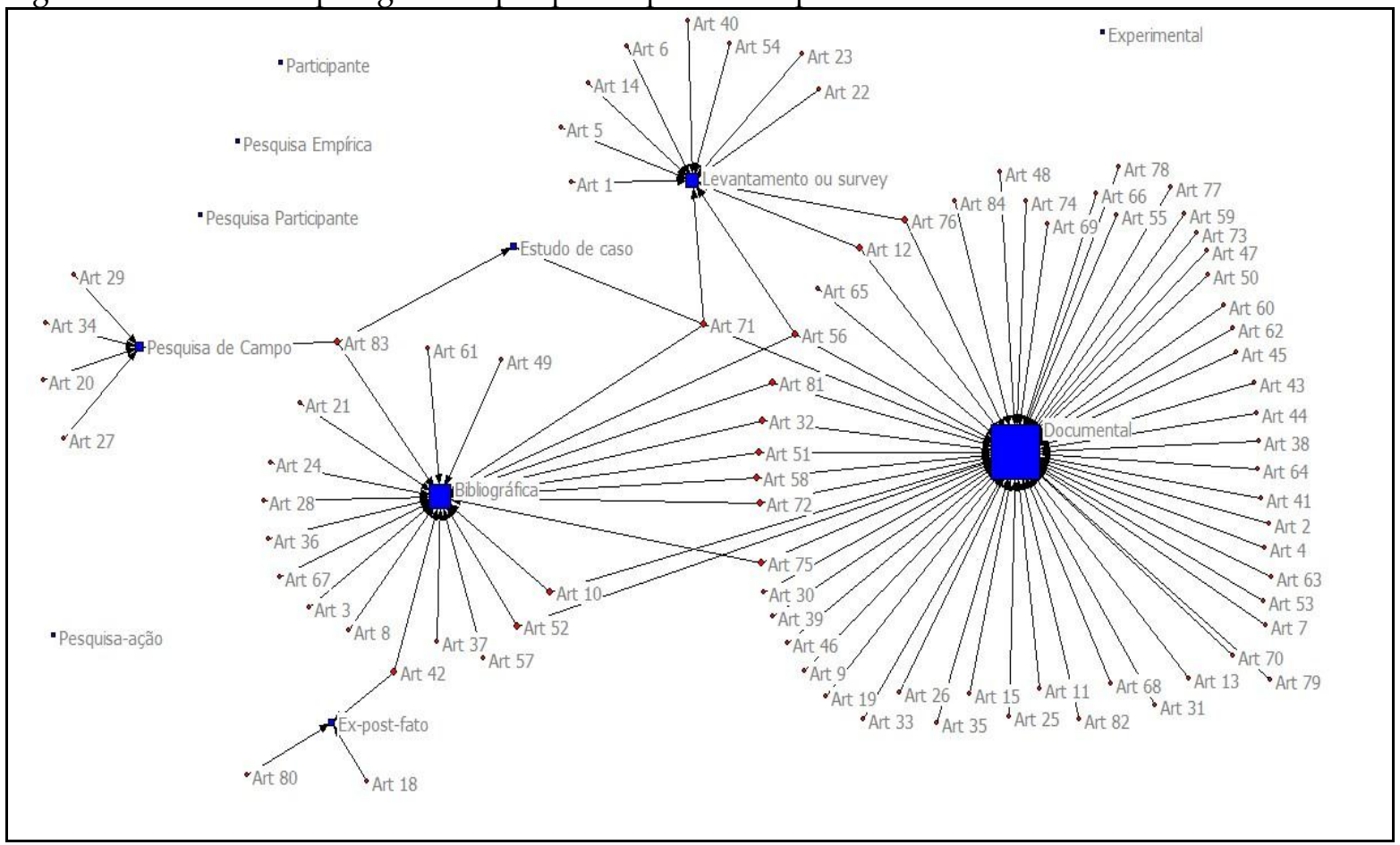

Fonte: Dados da pesquisa.

Constata-se a partir da Figura 5 a preponderância de pesquisas que utilizaram procedimentos documentais, seguida das pesquisas bibliográficas e dos levantamentos ou survey. Como pode-se perceber, não foram identificados estudos enquadrados como pesquisa participante, experimental, empírica, pesquisa-ação e pesquisa participante. Um melhor detalhamento acerca das tipologias pode ser observado a partir da tabela 1, observando que uma mesma pesquisa pode conter mais de um procedimento utilizado. 
Tabela 1 - Distribuição de frequência quanto aos procedimentos utilizados nas pesquisas

\begin{tabular}{l|c|c}
\hline \multicolumn{1}{c|}{ Procedimento } & Frequência & $(\%)^{*}$ \\
\hline Documental & 55 & 67 \\
Bibliográfica & 23 & 28 \\
Levantamento ou survey & 12 & 15 \\
Pesquisa de Campo & 5 & 6 \\
Ex-post-fatos & 3 & 4 \\
Estudo de Caso & 2 & 2 \\
\hline
\end{tabular}

Fonte: Dados da pesquisa.

Conforme Raupp e Beuren (2004), as pesquisas documentais baseiam-se em materiais que ainda não receberam um tratamento analítico ou que podem ser reelaborados de acordo com os objetivos da pesquisa, e sua notabilidade é justificada pelo fato de que se pode organizar informações que se encontram dispersas, conferindo aos documentos uma nova importância como fonte de consulta. Partindo-se do mesmo pressuposto anterior, a pesquisa documental provavelmente veio a ser a mais utilizada por possibilitar acesso a dados precisos e confiáveis de fácil e rápido acesso, permitindo que se descreva e analise fatos, buscando entender determinados comportamentos.

Quanto à abordagem do problema dos estudos analisados, verificou-se que prevaleceu a abordagem quantitativa, sendo que, dos 82 artigos analisados, 59 mostraram-se quantitativos, 31 qualitativos e 8 enquadram-se em ambos. Conforme pode ser observado na Figura 6.

Figura 6 - Redes das tipologias das pesquisas em relação ao problema

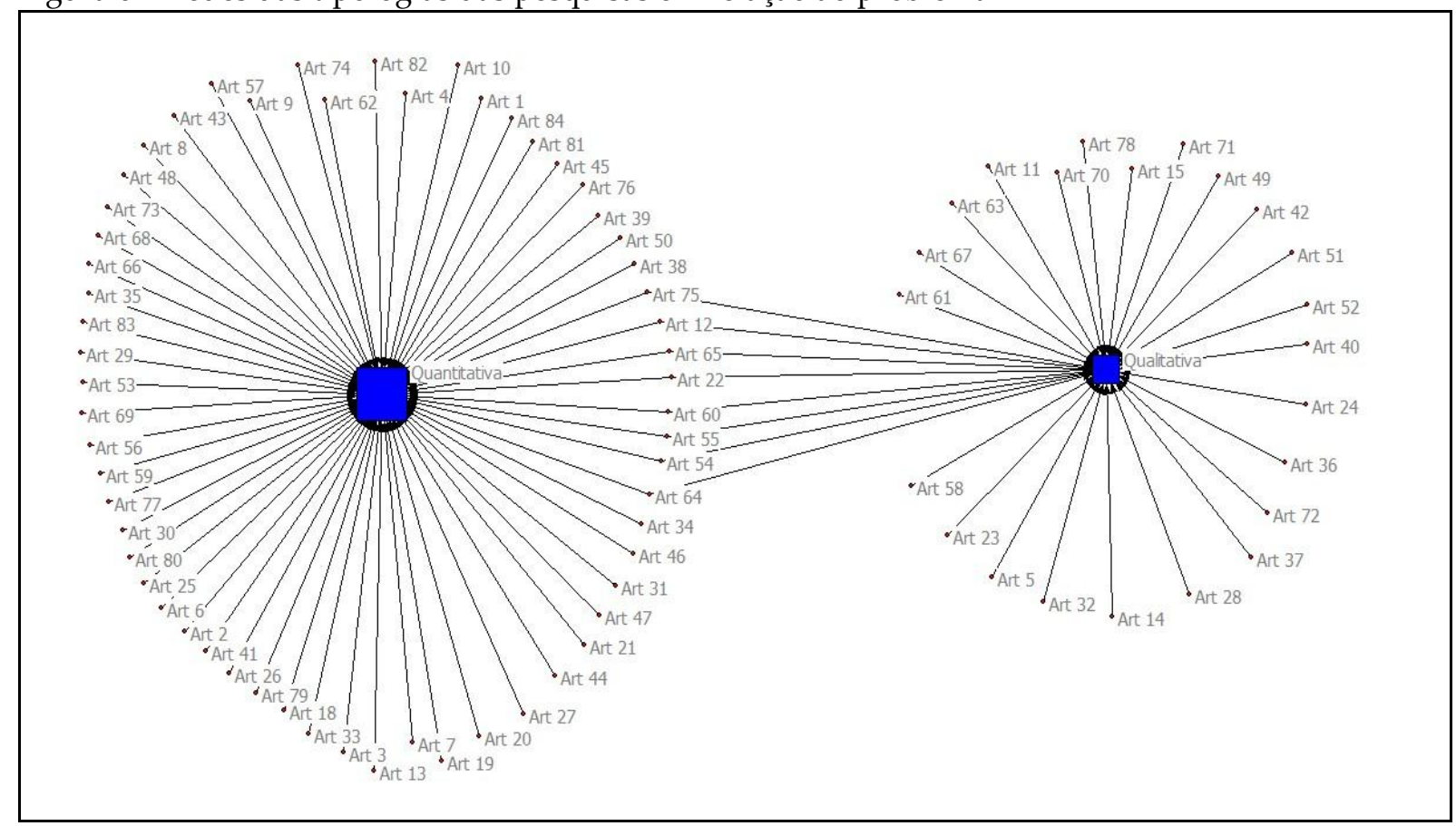

Fonte: Dados da pesquisa. 
De acordo com Raupp e Beuren (2004), a abordagem quantitativa caracterizase pelo emprego de métodos estatísticos, tanto na coleta como no tratamento dos dados e afirma que este procedimento não é tão profundo na busca do conhecimento da realidade dos fenômenos, uma vez que se preocupa com o comportamento geral dos acontecimentos. Percebe-se este resultado vai ao encontro do que foi abordado anteriormente em relação ao fato de que a maioria das pesquisas enquadra-se como descritiva e documental, pois as pesquisas quantitativas buscam entender um comportamento mais geral dos acontecimentos, assim como a pesquisa descritiva objetiva e assim como a pesquisa documental possibilita. Muito provavelmente, portanto, as pesquisas qualitativas são as pesquisas bibliográficas e exploratórias observadas nas Figuras 4 e 5 .

Um exemplo de pesquisa que utilizou de métodos quantitativos para a descrição e análise de fenômenos foi o de Monte et al. (2009) que teve como objetivo investigar se há relação entre as boas práticas de governança corporativa e a volatilidade na Bolsa de Valores.

A Figura 7 expõe as tipologias das pesquisas quanto aos instrumentos de pesquisa utilizados.

Figura 7 - Redes das tipologias de pesquisa quanto aos instrumentos de pesquisa

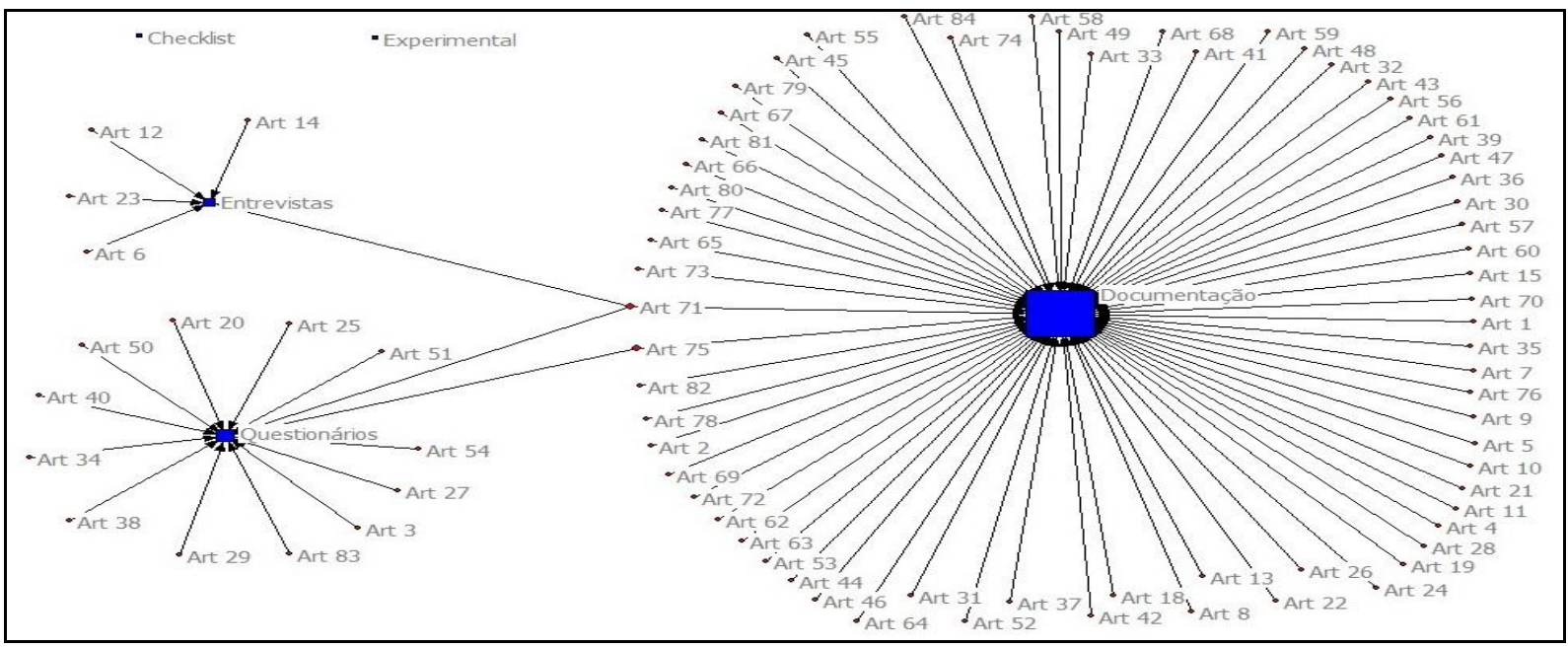

Fonte: dados da pesquisa

Conforme a Figura 7 pode-se verificar o predomínio da utilização da análise documental. Sendo que, dos 82 artigos analisados, 66 utilizaram documentos para a realização dos estudos, 16 utilizaram questionários e 4 realizaram entrevistas. Podese apontar ainda que dois artigos utilizaram mais de um instrumento de pesquisa para a realização do estudo, sendo o de Gabriel e Silveira (2011), que utilizaram documentos e questionários e o de Carioca et al. (2010), no qual utilizaram questionários, documentos e entrevista. Alguns exemplos de pesquisas que utilizaram apenas documentos são: Verhagem et al. (2011), no qual utilizaram as Demonstrações Financeiras Padronizadas - DFP de empresas do setor de siderurgia e metalurgia listadas 
na BM\&FBOVESPA do período de 2005 a 2009, por meio do website da BM\&FBOVESPA, e a pesquisa de Brugni et al. (2008), que utilizou do preço dos papéis de ações de empresas listadas na Bovespa, sendo os dados fornecidos Economática ${ }^{\circledR}$ e pela Comissão de Valores Mobiliários.

Em relação à análise dos dados, são apresentadas na Figura 8 quais foram as formas mais utilizadas.

Figura 8 - Redes dos métodos de análise dos dados

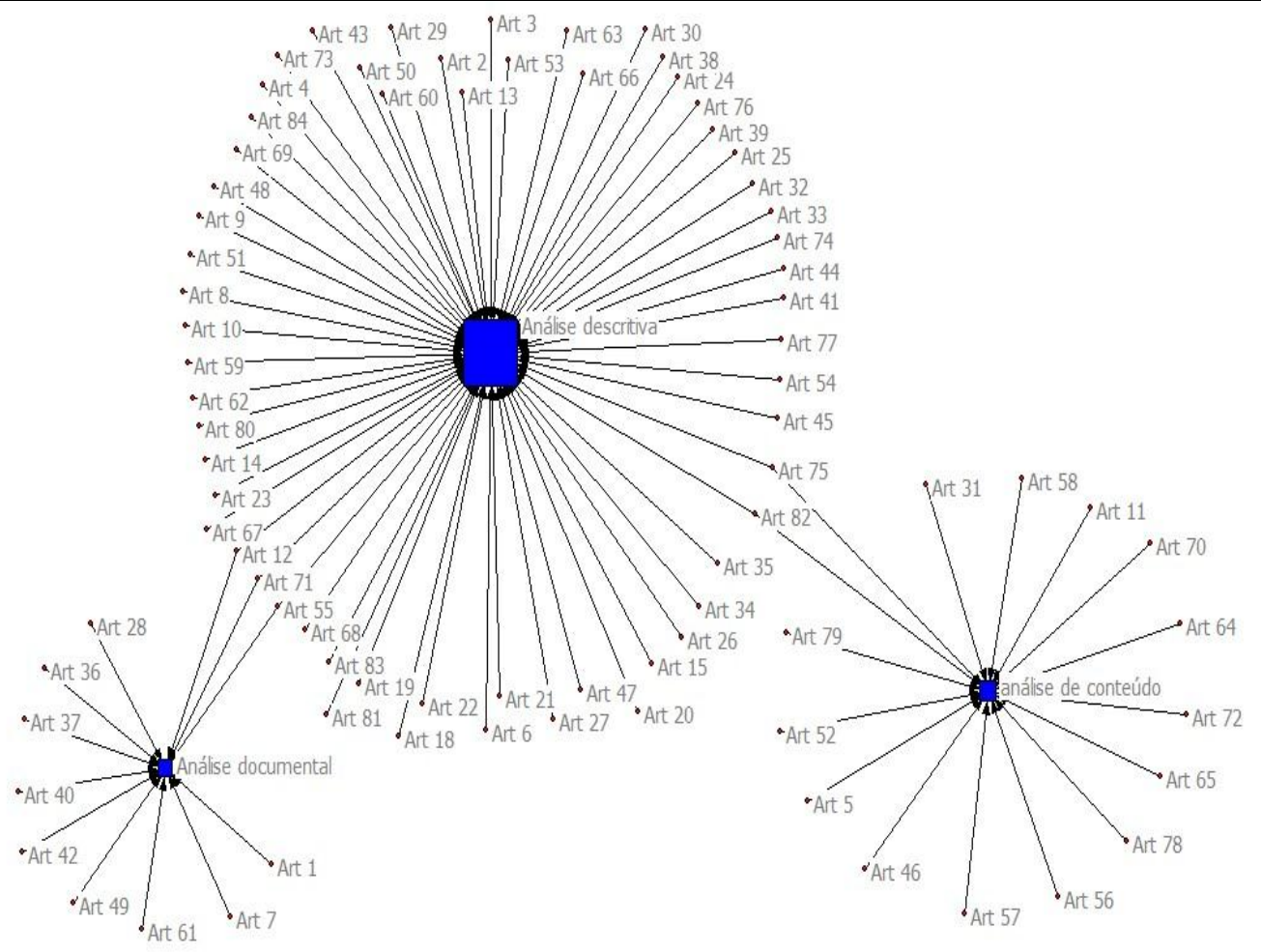

Fonte: Dados da pesquisa.

Verifica-se na Figura 8 que, quanto a análise dos dados, houve uma grande predominância da utilização de análise descritiva, seguida da análise de conteúdo e análise documental. Sendo, do total de 82 artigos, 59 análises descritivas, 16 análises de conteúdo e 12 análises documentais.

Conforme Beuren e Colauto (2004, p. 139), "de forma geral, todos os estudos que envolvem dados quantitativos, independente das questões, hipóteses ou pressupostos elaborados para a pesquisa, requerem análises descritivas". E ainda complementam apontando que "A análise descritiva se preocupa fundamentalmente em investigar o que é, ou seja, em descobrir as características de um fenômeno". Assim, conclui-se que o predomínio das análises descritivas se deve em parte ao grande número de pesquisas quantitativas e também a necessidade de verificar os reais impactos das práticas de governança corporativa para as empresas e para a sociedade. 


\section{CONSIDERAÇÕES FINAIS}

Esta pesquisa teve como objetivo mapear o perfil das publicações nos periódicos e congressos da área contábil, no período de 2000 a 2012 sobre governança corporativa. Para tanto, realizou-se uma pesquisa descritiva, documental, de abordagem quantitativa e análise descritiva. Foram publicados, entre os anos de 2000 a 2012, 82 artigos com o termo "Governança Corporativa” no título. Para a análise dos dados, elaboraram-se as redes com a ajuda do software UCINET $^{\circledR}$, em que apresentou-se informações referentes aos aspectos gerais e metodológicos dos artigos analisados.

Nos aspectos gerais, foram evidenciadas a quantidade de autores por artigo e os anos das publicações das pesquisas, e, nos aspectos metodológicos, as tipologias das pesquisas utilizadas quanto aos objetivos, quanto aos procedimentos, quanto à abordagem do problema, os instrumentos de pesquisa e os métodos de análise dos dados utilizados pelos estudos investigados.

Como resultado, obteve-se equilíbrio em relação a quantidade de autores, prevalecendo os artigos escritos por três autores. Em relação aos anos de publicação, o ano com maior número de publicações de artigos com "Governança Corporativa" contido no título foi o de 2011. Referente aos aspectos metodológicos, verificou-se que quanto aos procedimentos, a maioria das pesquisas enquadrou-se como descritiva, e quanto aos procedimentos, a maior parte classificou-se como documental. Em relação a abordagem do problema e os instrumentos de pesquisa utilizados, houve o predomínio da abordagem quantitativa e da utilização de documentação, e, quanto a análise dos dados, prevaleceu a análise descritiva.

Conclui-se que, pela quantidade razoável de artigos encontrados em um grande período de tempo e pelas incertezas que ainda acompanham o tema, se faz necessário um maior aprofundamento acerca do assunto. Adicionalmente, embora ainda rondem incertezas quanto aos impactos que resultam das práticas de governança, verificou-se que houve um maior número de pesquisas quantitativas em detrimento das pesquisas qualitativas, gerando estudos menos aprofundados que geralmente verificam apenas aspectos gerais dos acontecimentos em detrimento de estudos que geram análises mais profundas sobre a temática.

\section{REFERÊNCIAS}

ALMEIDA, M. A.; SANTOS, J. F.; FERREIRA, L. F. V. M.; TORRES, F. J. V. Governança corporativa e desempenho: um estudo das empresas brasileiras não listadas na Bovespa. Anais do $10^{\circ}$ Congresso USP de Controladoria e Contabilidade, São Paulo, 17 p., julho 2010. 
ANTONELli, R. A.; CLEMENTE, A.; CHEROBIM, A. P. M. S.; SCHERER, L. M. Adesão ou migração aos níveis diferenciados de governança corporativa e risco das ações. Anais do $1^{0}$ Congresso USP de Controladoria e Contabilidade, São Paulo, 15 p., julho 2011.

ARAUJO, L. C. G. Organização, sistemas e métodos e as tecnologias de gestão organizacional: arquitetura organizacional, benchmarking, empowerment, gestão pela qualidade total, reengenharia. 3. ed. São Paulo: Atlas, 2010.

BATISTELLA, F. D.; CORRAR, L. J.; BERGMANN, D. R.; AGUIAR, A. B. Retornos de Ações e Governança Corporativa: Um Estudo de Eventos. Anais do $4^{\mathbf{0}}$ Congresso USP de Controladoria e Contabilidade, São Paulo, 15 p., outubro 2004.

BEUREN, I. M. (Org.). Como elaborar trabalhos monográficos em contabilidade: teoria e prática. 2. ed. São Paulo: Atlas, 2004. 195 p.

BIANCHI, M.; SILVA, C. V.; GELATTI, R.; ROCHA, J. M. L. A evolução e o perfil da governança corporativa no Brasil: um levantamento da produção científica do Enanpad entre 1999 e 2008. Revista Contexto, Porto Alegre, v. 9, n. 15, 2009.

BORGES, G. F.; AVELAR, E. A.; NASCIMENTO, J. P. B.; MAFRA, F. L. N. Ensino de contabilidade: uma análise da produção científica nacional sob a perspectiva da bibliometria e sociometria. Anais do $12^{\circ}$ Congresso USP de Controladoria e Contabilidade, São Paulo, 16 p., julho/2012.

BRUÈRE, A. J.; SILVA, W. M.; SANTOS, J. F. Aspectos da governança corporativa de empresas listadas na Bovespa: um estudo exploratório sobre a composição e perfil dos conselhos de administração. BASE - Revista de Administração e Contabilidade da Unisinos, v. 4, n. 2, p. 149-159, 2007.

BRUGNI, T. V.; SARLO NETO, A.; BORTOLON, P. M.; GOÉS, A. O. S. Uma avaliação da Governança Corporativa à luz do modelo de Ohlson: Evidências empíricas no mercado de capitais brasileiro. Revista ANPCONT, Florianópolis, jul. 2012. Disponível em: <https://www.furb.br/especiais/download/568098-291226/MFC\%20262.pdf>. Acesso em: 10 jan. 2013.

CAMPOS, G. M.; DINIZ, J. A.; MARTINS, G. A. Fronteiras da pesquisa sobre governança corporativa: uma análise epistemológica. Enfoque Reflexão Contábil, v. 30, n. 2, p. 36-51, 2011.

COLAUTO, R. D.; BEUREN, I. M. Apresentação e estrutura do trabalho monográfico 
de acordo com as normas da ABNT. In: BEUREN, Ilse Maria (Org.). Como elaborar trabalhos monográficos em contabilidade: teoria e prática. 3. ed. São Paulo: Atlas, 2012, p. 145-185

DUTRA, S. E. Governança Corporativa em empresas estatais no Novo Mercado: Uma discussão crítica sobre o Banco Nossa Caixa. Anais do $12^{\circ}$ Congresso USP de Controladoria e Contabilidade, São Paulo, 16 p., julho/2012.

GABRIEL, F.; SILVEIRA, A. M. Qualidade da Informação Contábil e Análise de sua Relação com a Estrutura de Governança Corporativa das Firmas no Brasil. Anais do $11^{\underline{o}}$ Congresso USP de Controladoria e Contabilidade, São Paulo, 19 p., julho/2011.

GIL, A.C. Métodos e técnicas de pesquisa social. 6. ed. São Paulo: Atlas, 2008.

GUBIANI, C. A.; SANTOS, V.; SILVA, J. O.; RAUSCH, R. B. A Internacionalização em Trabalhos Publicados no EnANPAD no Período de 2005 a 2009: Uma Análise Bibliométrica. Revista Seminários em Administração - Semead, São Paulo, set. 2010. Disponível em:

$<$ http://www.ead.fea.usp.br/semead/13semead/resultado/an_resumo.asp?cod_trabalh $\mathrm{o}=225>$. Acesso em: 10 jan. 2013.

INSTITUTO BRASILEIRO DE GOVERNANÇA CORPORATIVA. Código das Melhores Práticas de Governança Corporativa. 4. ed. Instituto Brasileiro de Governança Corporativa. São Paulo: IBGC, 2009.

<www.ibgc.org.br/Download.aspx?Ref=Codigos\&CodCodigo=47> Acesso em: 13 nov. 2012.

MACHADO, J. H;. FAMÁ, R. Ativos Intangíveis e Governança Corporativa no Mercado de Capitais Brasileiro. Anais do $11^{\circ}$ Congresso USP de Controladoria e Contabilidade, São Paulo, 17 p., julho 2011.

MONTE, P. A.; REZENDE, I. C. C.; TEIXEIRA, G. S.; BESARRIA, C.N. Existe relação entre Governança Corporativa e volatilidade? Um estudo a partir da formação de carteiras. Revista Contabilidade Vista E Revista, Belo Horizonte, v. 21, n. 2, p. 15-44, 2010.

NARDI, P. C. C.; NAKAO, S.H. Impacto da entrada nos níveis diferenciados de governança corporativa sobre a imagem institucional das empresas. Revista Contabilidade Vista E Revista, Belo Horizonte, v. 19, n. 2, p. 85-111, 2008. 
OLIVEIRA, D. P. R. Governança Corporativa na prática: integrando acionistas, conselho de administração e diretoria executiva na geração de resultados. 2 ed. São Paulo: Atlas, 2010.

PEDREIRA, E. B.; SANTOS, J. O. Análise da relação entre o índice de governança corporativa e o preço das ações de empresas do setor de papel e celulose. Anais do $4^{\underline{o}}$ Congresso USP de Controladoria e Contabilidade, São Paulo, 15 p., outubro/2004.

PUNSUVO, F. R.; KAYO, E. K.; BARROS, L. A. B. C. O ativismo dos fundos de pensão e a qualidade da governança corporativa. Revista Contabilidade Finanças, 2007, v.18, n. 45 , p. $63-72$.

RAUPP, F. M.; BEUREN, I. M. Metodologia da pesquisa aplicável às ciências sociais. In: BEUREN, Ilse Maria (Org.). Como elaborar trabalhos monográficos em contabilidade: teoria e prática. 3.ed. São Paulo: Atlas, 2012. p. 76-97.

ROSSETI, J. P.; ANDRADE, A. Governança Corporativa: Fundamentos, Desenvolvimento e Tendências. 6 ed. São Paulo: Atlas, 2012.

SILVA, A. L. C. Governança Corporativa e sucesso empresarial: melhores práticas para aumentar o valor da firma. São Paulo: Saraiva, 2006.

SILVA, E. C. Governança Corporativa nas empresas: guia prático de orientação para acionistas, investidores, conselheiros de administração, executivos, gestores, analistas de mercado e pesquisadores. 2 ed. São Paulo: Atlas, 2010.

SLOMSKI, V.; MELLO, G. R.; TAVARES FILHO, F.; MACÊDO, F. Q. Governança Corporativa e Governança na Gestão Pública. São Paulo: Atlas, 2008.

SOUZA, F. C.; BORBA, J. A. Governança corporativa e remuneração de executivos: uma revisão de artigos publicados no exterior. Contabilidade Vista $\mathcal{E}$ Revista, v. 18, n. 2, p. 35-48, 2007.

SOUZA, T. M.G. Governança corporativa e o conflito de interesses nas sociedades anônimas. São Paulo: Atlas, 2005.

VERHAGEM, J. A.; SANTOS, P. S. A.; BEZERRA, F. A. Gerenciamento de resultados contábeis por meio de decisões operacionais e a governança corporativa: uma análise nas indústrias siderúrgicas e metalúrgicas. Anais do 11ํㅡㄹ Congresso USP de Controladoria e Contabilidade, São Paulo, 17 p., julho/2011. 